\title{
Retrieval of stratospheric aerosol density profiles from SCIAMACHY limb radiance measurements in the $\mathrm{O}_{2} \mathrm{~A}$-band
}

\author{
B. Ovigneur, J. Landgraf, R. Snel, and I. Aben \\ Netherlands Institute for Space Research (SRON), Utrecht, The Netherlands \\ Received: 15 February 2011 - Published in Atmos. Meas. Tech. Discuss.: 15 March 2011 \\ Revised: 3 October 2011 - Accepted: 14 October 2011 - Published: 2 November 2011
}

\begin{abstract}
In this paper we present an approach to retrieve stratospheric aerosol number densities in the altitude range 10-40 km from SCIAMACHY limb radiance measurements in the spectral range of the $\mathrm{O}_{2} \mathrm{~A}$ absorption band, near $760 \mathrm{~nm}$. Here, the characteristic light paths differ for the measured light in the $\mathrm{O}_{2} \mathrm{~A}$-band and in the spectral continuum next to the absorption band. This difference is used to distinguish the effect of stratospheric aerosol scattering and ground reflection on the limb measurement. The capability to disentangle both effects is illustrated for SCIAMACHY limb observations over the Libyan desert, where the measurements are not affected by tropospheric clouds. Comparison of the SCIAMACHY retrieval and the SAGE II aerosol extinction product between $75^{\circ}$ southern and northern latitude shows the clear need for prior knowledge of the mean size of the stratospheric aerosol for the SCIAMACHY retrieval. We found best agreement between SCIAMACHY and SAGE II aerosol extinction for the period 2003-2005 for a prior choice of the mean aerosol size radius of $0.2 \mu \mathrm{m}$. The overall agreement between both data sets is in the range $<50 \%$ root mean square difference at $14-30 \mathrm{~km}$ with a minimum of $30 \%$ at $22 \mathrm{~km}$.
\end{abstract}

\section{Introduction}

Fifty years ago, Junge and Manson (1961) reported balloonborne measurements of the abundance of stratospheric aerosol. Junge and Manson observed a general decrease of the aerosol particle concentration with altitude, but just above the tropopause a layer of larger particles was detected with a

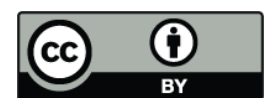

Correspondence to: J. Landgraf (j.landgraf@sron.nl) vertical extension of several kilometers. This so-called Junge layer consists of supercooled sulfuric acid droplets with different weight percentages of $\mathrm{H}_{2} \mathrm{SO}_{4}$ in the aerosol and with varying size between 0.1 and $1 \mu \mathrm{m}$ in diameter.

An important source of the stratospheric aerosol are volcanic eruptions, which can inject a large amount of $\mathrm{SO}_{2}$ into the stratosphere, where it is photo-oxidized to sulfuric acid (Hofmann and Rosen, 1983; Oberreck et al., 1983; Deshler et al., 1992, 1993). Hence, volcanic stratospheric aerosol influences directly the heat budget of the atmosphere by absorbing, scattering and emitting radiation depending on their optical properties (Mugnai et al., 1978; McCormick et al., 1995; Solomon, 1999). Close to the tropopause the stratospheric aerosol may affect the formation of cirrus clouds and so it can have an indirect effect on climate and atmospheric photochemistry (Kärcher and Ström, 2003; Penner et al., 2009). Non-volcanic sources of stratospheric aerosol include the transport of OCS from the lower atmosphere to the stratosphere, where it is photochemically transformed into $\mathrm{SO}_{2}$ (Crutzen, 1976). At present, it is still an outstanding question whether human activities significantly affect the stratospheric aerosol abundance (Hofmann et al., 2009). Next to its climate relevance, stratospheric aerosol interacts with nitrous oxide and chlorine reservoir species (Crutzen, 1970; Fahey et al., 1993) and even small enhancements of the background aerosol level are sufficient to repartition the ozone balance. Thus it is difficult to assess long-term ozone trends without sufficient knowledge on stratospheric aerosol variability.

Several spacecraft-based spectrometers have been launched to monitor stratospheric aerosol through solar occultation, starting with the Stratospheric Aerosol Measurement II (SAM II), which was successfully launched in 1978 (McCormick et al., 1979). Shortly after, in 1979, the Stratospheric Aerosol and Gas Experiment I (SAGE

Published by Copernicus Publications on behalf of the European Geosciences Union. 


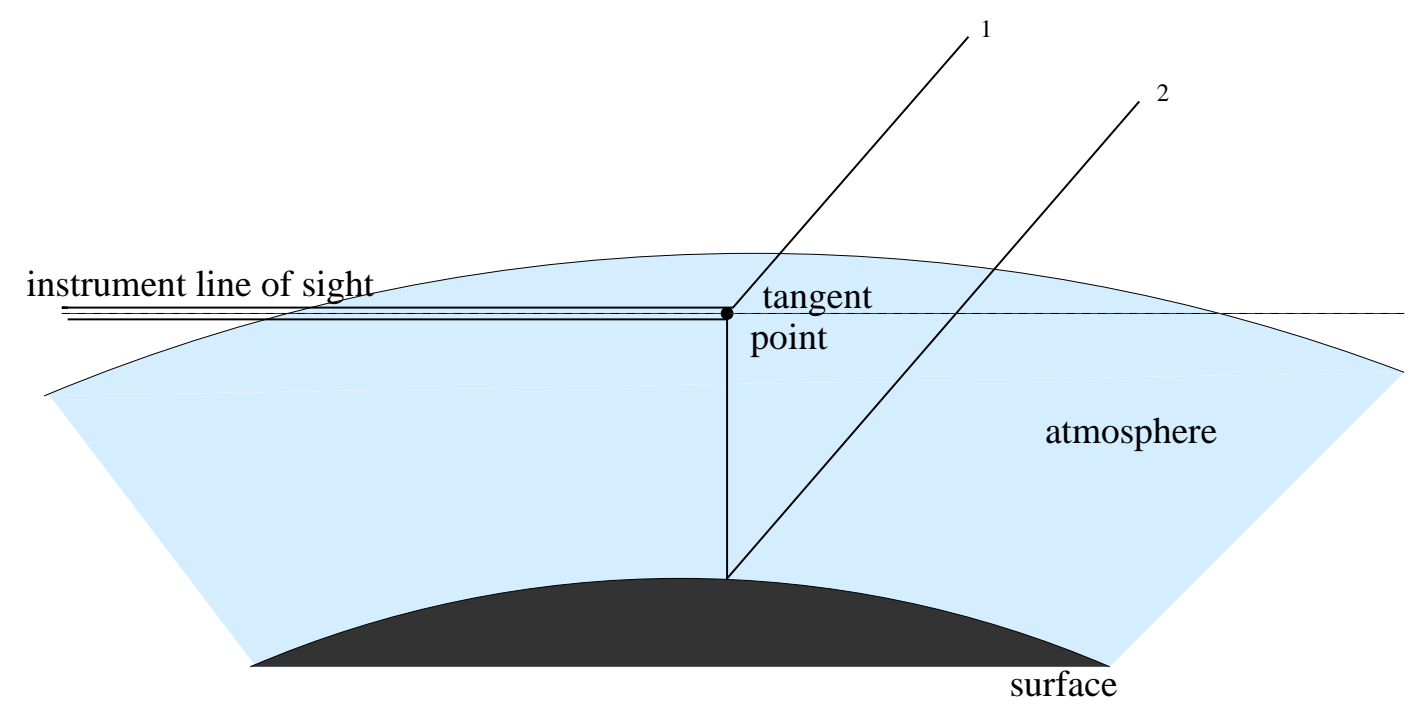

Fig. 1. Two relevant light paths for limb observations in the longwave visible and near infrared. The effect of multiple atmospheric scattering is not presented.

I, McCormick et al., 1982) was launched as the first of a series of three missions dedicated to measure stratospheric aerosols. SAGE I was operational for 34 months. In 1984 and 2001, the SAGE mission got continued with the launch of SAGE II (Mauldin et al., 1985; Bingen et al., 2004a,b) and of SAGE III (Yue, 2000; Chu et al., 2002). After nearly $21 \mathrm{yr}$, the SAGE II instrument was powered off in 2005. The Meteor-3M mission, along with the SAGE III instrument, was terminated shortly after, in 2006. The Improved Limb Atmospheric Spectrometer-II (ILAS-II) onboard the Advanced Earth Observing Satellite-II (ADEOS-II) was successfully launched in 2002 which also observed the atmosphere through solar occultation. However after 10 months ADEOS-II lost its function, and only seven months of data were acquired by the measurements of vertical profiles of aerosol extinction coefficients (Saitoh et al., 2006). Still functional is the Atmospheric Chemistry Experiment (ACE, Bernath et al., 2005) which was launched 2003. Overall this unique series of satellite missions provides a set of more than $40 \mathrm{yr}$ of solar occultation measurements of stratospheric aerosols.

Solar occultation measurements allow a straight forward and robust retrieval of aerosol extinction profiles but with the downside of spatially sparse measurements. Alternatively, one can observe stratospheric aerosol from space employing limb viewing geometry, which generally provides a better geographic coverage. The OSIRIS (Bourassa et al., 2007) and SCIAMACHY (Bovensmann et al., 1999) spectrometers are both limb sounding spectrometers. They were launched in 2001 and 2002, respectively, and are both still fully operational. SCIAMACHY is a grating spectrometer, whose primary mission objective is to perform global measurements of trace gases in the troposphere and in the stratosphere. It measures the solar radiation in nadir, limb and occultation geometry, where the light is attenuated along its path through the Earth atmosphere. The relatively high spectral resolution $(0.2 \mathrm{~nm}$ to $0.5 \mathrm{~nm})$ between $240 \mathrm{~nm}$ to $1700 \mathrm{~nm}$, and in selected regions between $2000 \mathrm{~nm}$ and $2400 \mathrm{~nm}$, makes it suited for the detection of stratospheric aerosols (see also Taha et al., 2011). In this paper we present a novel approach in order to retrieve stratospheric aerosol density profiles from SCIAMACHY limb measurements in the $\mathrm{O}_{2}$ A-band. In this spectral range the different atmospheric paths of the measured light allows to disentangle the effect of aerosols and surface reflection on the limb measurement. So, an effective Lambertian surface albedo and a vertical distribution of aerosol density between 10 and $35 \mathrm{~km}$ can be retrieved simultaneously from SCIAMACHY limb radiance measurements. This paper is structured as follows: Sect. 2 analyzes the effect of stratospheric aerosols on SCIAMACHY limb measurements over the Libyan desert between 2003 and 2009. Section 3 describes the retrieval approach and in Sect. 4 the retrieval results are discussed, including a comparison with spatially co-located SAGE II measurements. Finally, the paper is summarized in Sect. 5.

\section{Effect of Aerosols on SCIAMACHY limb observations}

To demonstrate the sensitivity of limb radiance measurements in the visible and near infrared on aerosol properties, we consider SCIAMACHY limb measurements at $500 \mathrm{~nm}$ over the Libyan desert for the period 2004-2009. According to the International Satellite Cloud Climatology Project (ISCCP) cloud information (Rossow and Schiffer, 1999) this region shows very low cloud coverage all the year round. So, 


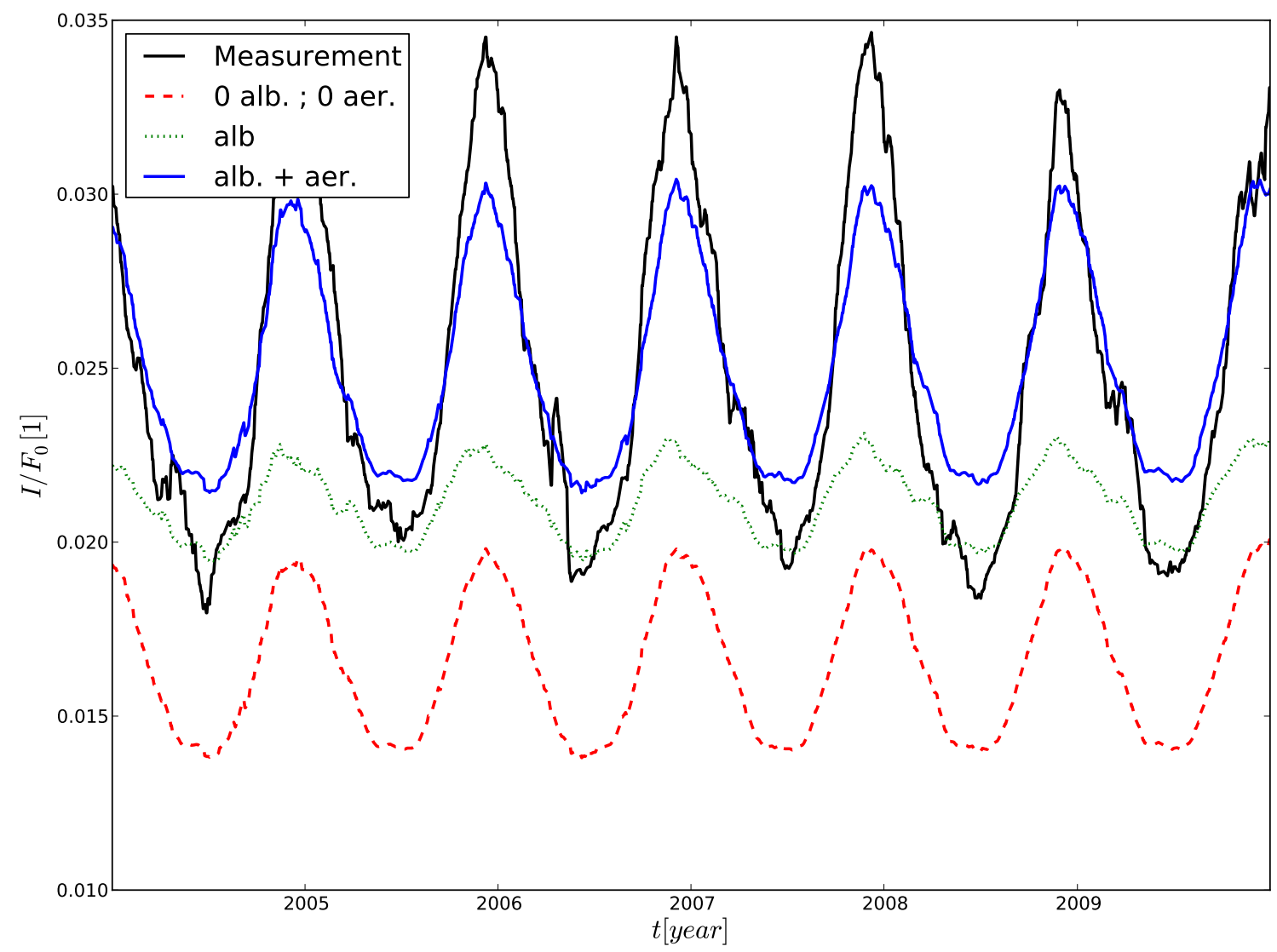

Fig. 2. SCIAMACHY limb radiance measurements at $500 \mathrm{~nm}$ over the Libyan desert for tangent height of $25 \mathrm{~km}$ as a function of time (black solid line). The Figure shows also three different model simulations using the solar and viewing geometry of the limb observations: for only Rayleigh scattering and no surface reflection (red dashed line), for only Rayleigh scattering and a Lambertian surface albedo of 0.30 (green dotted line), for Rayleigh and background aerosol scattering and a Lambertian surface albedo of 0.30 (blue solid line).

the measured light is mainly direct sunlight which is either scattered at the tangent point in the SCIAMACHY viewing direction, or reflected at the Earth surface and subsequently scattered in the instrument's line of sight (see Fig. 1). Here the light can be scattered either by air molecules or stratospheric aerosols. At $500 \mathrm{~nm}$ atmospheric absorption by ozone is weak and thus its effect on the measurement is small. The Libyan desert is located around $23^{\circ}$ northern latitudes and so, the solar zenith angle varies between $27^{\circ}$ in summer and $70^{\circ}$ in winter at the time of the SCIAMACHY observation. For the limb viewing geometry of SCIAMACHY this causes a variation of the scattering angle of singly scattered light at the tangent point between $55^{\circ}$ in winter and $100^{\circ}$ in summer. It means that in winter the single scattering geometry is closer to the forward peak of the scattering phase function than in summer. As a result the SCIAMACHY limb radiance varies seasonally as depicted in Fig. 2 for a tangent height of $25 \mathrm{~km}$. To illustrate the different effects of aerosol scattering, Rayleigh scattering, and surface reflection on the measurement, the figure shows different limb radiance simulations for the corresponding measurement geometries. Here we employ the full spherical scalar radiative transfer model of Walter et al. (2006), which includes multiple scattering of light. For an aerosol free atmosphere without surface reflection (red dashed line), the measurements are significantly underestimated by the simulations. Also, the seasonal variation is too weak in the simulation. Enhancing the surface albedo to 0.30 increases the modeled radiance level, but reduces the seasonal variability (green dotted line). The upward radiance at surface level due to Lambertian reflection of the direct solar beam is proportional to the flux $\mu_{\mathrm{o}} F_{\mathrm{o}} \exp \left(-\tau_{\mathrm{o}}\right)$ where $\mu_{\mathrm{o}}$ is the cosine of the local solar zenith angle, $F_{\mathrm{o}}$ is the extraterrestrial solar irradiance, and $\tau_{\mathrm{o}}$ is the optical thickness along the solar beam from top of the model atmosphere to the surface. At $500 \mathrm{~nm}$, $\tau_{\mathrm{o}}$ is very small and so the seasonal dependence of the upwelling intensity at the surface is governed by $\mu_{\mathrm{o}}$. Thus, the upwelling intensity is in antiphase with the single scattering contribution of the measurement, and so enlarging the surface albedo reduces the seasonal variability of the measurement simulation. The blue solid line of Fig. 2 shows a model simulation where we have also added a stratospheric 


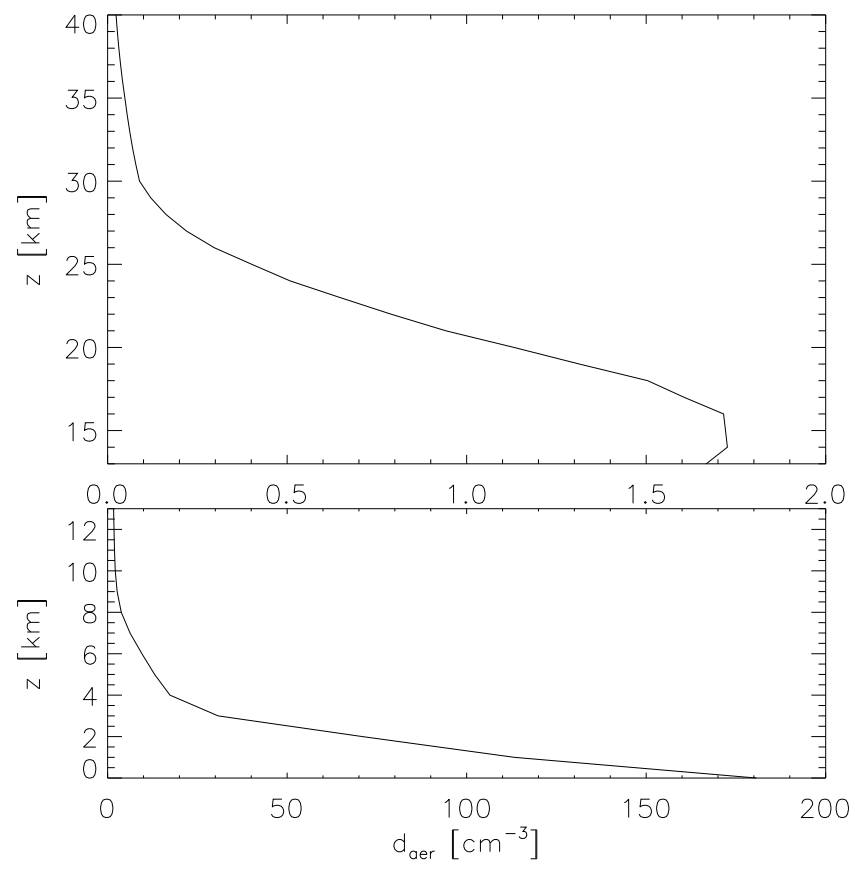

Fig. 3. Profile of aerosol particle density adopted from Loughman et al. (2004). The upper panel shows the stratospheric part of the profile and lower panel the tropospheric part. The profile refers to a background load of stratospheric aerosol.

background aerosol to the model atmosphere. Here, the aerosol optical properties are adopted from Loughman et al. (2004) and the corresponding stratospheric aerosol density profile is shown in Fig. 3. Due to the strong forward peak of the aerosol scattering phase function, stratospheric aerosols enhance the seasonal variation of the simulation by increasing the single scattering signal during the winter months.

To compare SCIAMACHY measurements and simulations at different tangent heights, we consider the mean December and June radiances for the period 2004-2009. Figure 4 shows the difference between the measurement and different model simulations as a function of height. Ignoring surface reflection and scattering by stratospheric aerosol results in an underestimation of the measurements by the simulations.

During the winter month the effect is largest around 20$25 \mathrm{~km}$, which hints at the presence of stratospheric aerosols. Surface reflection with an Lambertian albedo of 0.30 enhances the simulation by about the same fraction at all altitudes. This can be explained by the fact that at $500 \mathrm{~nm}$ atmospheric absorption and scattering are weak and so, the relative contribution of light that is reflected at the surface is only governed by the scattering properties at the satellite line of sight. The extinction of light between the surface and the scattering point on the line of sight is of little relevance. When we introduce a stratospheric background aerosol in the simulation, we also see an increase of the radiances, which is largest around $20-25 \mathrm{~km}$. Due to that, we expect that adjusting both the surface albedo and the aerosol profile in the lower stratosphere may lead to an improved fit to the data.

Also for the summer month, an albedo of 0.30 enhances the simulated limb radiance signal by nearly the same fraction at all altitudes. However, the aerosol effect is much smaller and causes only a significant change in the limb radiance between 20 and $35 \mathrm{~km}$, which hints at a reduced aerosol sensitivity of SCIAMACHY limb measurements for high solar elevation during summer months.

Figures 2 and 4 indicate that a proper description of SCIAMACHY limb radiance measurements requires knowledge of both the surface albedo and stratospheric aerosol abundances for each individual sequence of limb measurements. Normalizing the limb radiances with respect to a higher tangent height removes a significant part of the albedo sensitivity of the measurement, but retains the sensitivity to stratospheric aerosols. This approach is chosen e.g. by Taha et al. (2011) to retrieve stratospheric aerosol abundances. This paper presents a different approach, where both surface albedo and stratospheric aerosol density profiles are retrieved simultaneously from SCIAMACHY limb measurements at the spectral range of the $\mathrm{O}_{2}$ A-band, near $760 \mathrm{~nm}$. In this manner, one fully accounts for the sensitivity of the limb radiance measurements with respect to both surface reflection and stratospheric aerosol scattering.

\section{Retrieval approach}

For the simultaneous retrieval of stratospheric aerosol profiles and surface albedo, we make use of the fact that the measured light mainly follows two characteristic light paths as indicated in Fig. 1. Along the singly scattered light path the amount of measured light is governed by extinction and the scattering probability at the instrument line of sight. Increasing stratospheric aerosol at the tangent point increases the amount of light traveling from the tangent point to the satellite. When integrating the scattering source along a light path an enhanced aerosol abundance can also cause an attenuation of the signal because of scattering into directions other than the direction of integration. The second path includes the reflection of light at the Earth surface and thus increasing surface reflection has the same effect on the limb radiance as increasing the amount of aerosol at the tangent point. For weak atmospheric absorption the relative effect of surface reflection is very similar at different tangent heights (as discussed in the previous section). To retrieve both a stratospheric aerosol profile and surface properties from limb radiance measurements, one may neglect the effect of stratospheric aerosol on limb radiance measurements at higher tangent point. Subsequently, these measurements can be used to retrieve surface albedo. The drawback of this approach is twofold: due to the decrease of the measurement signal at higher tangent height the relative effect of 

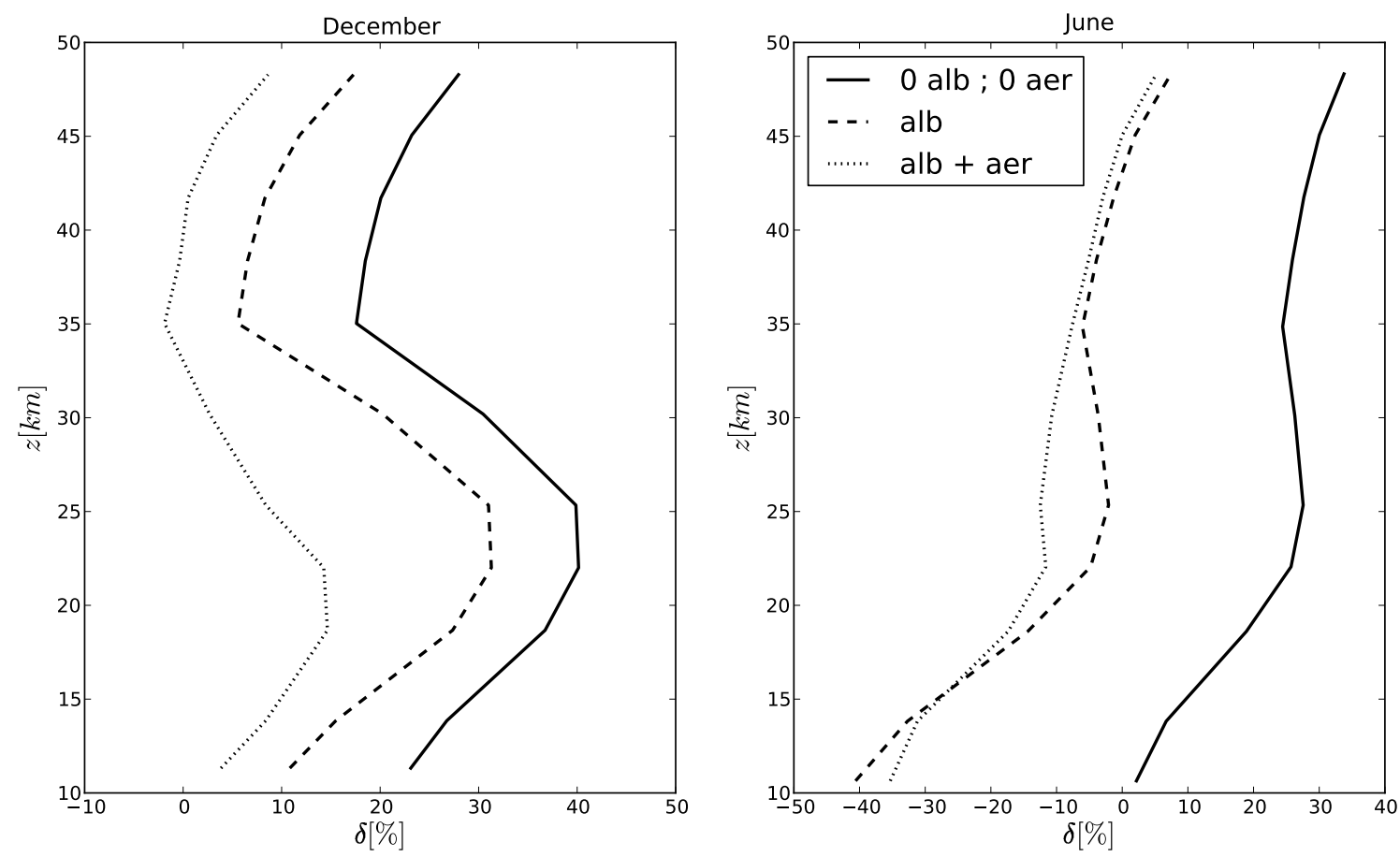

Fig. 4. Differences between monthly mean SCIAMACHY radiances and model simulations (measurement - simulation) as a function of tangent height for December (left panel) and June (right panel) for the period 2004-2009. The model configurations are the same as in Fig. 2.

measurement biases like spatial straylight increases. Moreover, limb measurements at high tangent heights are affected by stratospheric aerosols because of the extinction of light by aerosol scattering along the second light path in Fig. 1. Depending mainly on solar geometry the aerosol optical depth along this light path can be significant and so a seasonal bias can be introduced.

Alternatively, we propose to use limb measurements at different absorption depths of the $\mathrm{O}_{2}$ A-band including the spectral continuum. Assuming a constant surface albedo over wavelength, one is able to disentangle the measurement information on albedo and on aerosol concentration due to the different penetration depth of light. For the retrieval the forward model $\boldsymbol{F}$ in

$\boldsymbol{y}=\boldsymbol{F}(\boldsymbol{x}, \boldsymbol{b})+\mathbf{e}_{y}$

has to be inverted, where $\boldsymbol{y}$ is the measurement vector, and $\boldsymbol{x}$ is the state vector, which has the parameters to be retrieved as its components. The forward model parameter vector $\boldsymbol{b}$ contains other model parameters, which have to be chosen a priori, and $\mathbf{e}_{y}$ combines measurement and forward model errors. For this study, we use SCIAMACHY level $1 \mathrm{~b}$ version 7 data. The measurement vector is defined by a limb scan with tangent heights between 9.5 and $40 \mathrm{~km}$ and at three wavelengths, 756, 761, and $772 \mathrm{~nm}$. The shortest and longest wavelength belong to the spectral continuum, whereas the center wavelength is subject to strong oxygen absorption at the lower and middle stratosphere. The height range of the retrieval is determined by two aspects. First, most of stratospheric aerosol is located below $30 \mathrm{~km}$, and so the retrieval captures the most relevant height range. Also, Fig. 5 illustrates that above $44 \mathrm{~km}$ the $\mathrm{O}_{2} \mathrm{~A}$-band is observed as emission lines in the spectrum. The source of this emission is dayglow which typically originates from direct photodissociation, photoexcitation, and excitation by fast electrons, or ion recombination (Buchholtz et al., 1986; Slanger and Copeland, 2003). Because atmospheric emission is not taken into account by our forward model we consider only limb measurements below $40 \mathrm{~km}$ tangent height for the retrieval. The retrieval error which is caused by neglecting atmospheric emission is estimated in Sect. 4.

In the spectral range of the $\mathrm{O}_{2}$ A-band multiple scattered light can contribute up to $20 \%$ to the total limb radiance. To simulate the limb radiances at the three wavelengths with the SCIAMACHY spectral resolution of $0.5 \mathrm{~nm}$, limb radiances have to be calculated with a line-by-line spherical radiative transfer model on a spectral sampling of at least $0.01 \mathrm{~nm}$. Overall, this makes the forward model simulations computationally demanding. To simplify matters we calculate in each iteration of the retrieval the single scattering contribution online, whereas the multiple scattering contribution is approximated by a look-up table as a function of solar geometry, viewing geometry, and surface albedo. The look-up table is precalculated for the background aerosol scenario in Fig. 3. The overall error of the radiance simulation is estimated to be $\leq 1 \%$ for present-day stratospheric aerosol loading. 


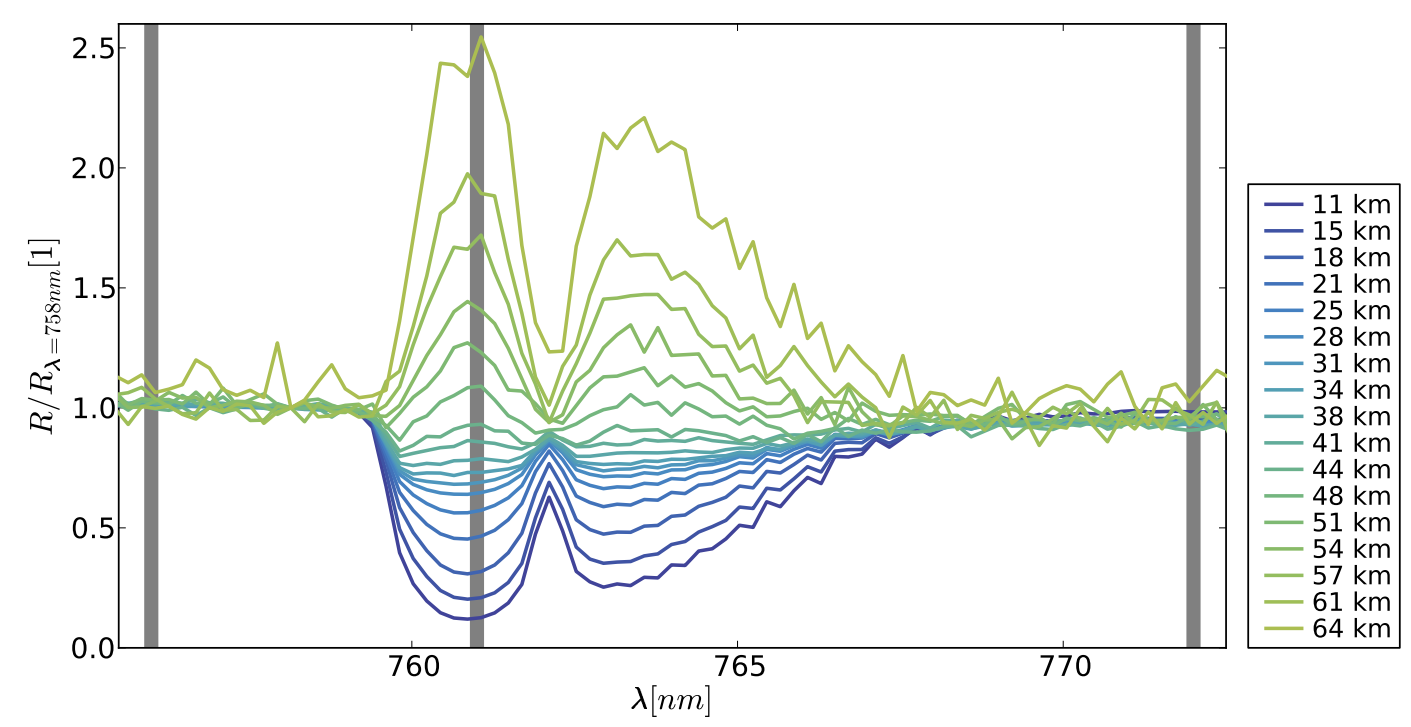

Fig. 5. SCIAMACHY limb radiance measurements in the $\mathrm{O}_{2}$ A-band normalized to the radiance at $758 \mathrm{~nm}$ for different tangent heights. The vertical lines indicate the wavelengths used in the retrieval.

The state vector $\boldsymbol{x}$ of the retrieval consists of the Lambertian surface albedo and the aerosol density profile, gridded on $3.3 \mathrm{~km}$ thick layers between 10 and $40 \mathrm{~km}$. Here, the layer thickness is chosen such that each aerosol element of the state vector can be assigned one-to-one to a limb measurement. Above $40 \mathrm{~km}$, we assume an exponential aerosol height distribution with a relative decrease $\exp (-c \Delta z)$ with $c=6 \cdot 10^{-5} \mathrm{~m}^{-1} . \Delta z$ represents the altitude difference with respect to $40 \mathrm{~km}$ altitude. The model parameter vector $\boldsymbol{b}$ contains the description of the aerosol micro-physical properties. For this study, we assume that the stratospheric aerosol consists of spherical droplets of $25 \%$ sulfuric acid and $75 \%$ water. The aerosol size is described by a mono-modal lognormal distribution function with a variance of $0.25 \mu \mathrm{m}$ and with an effective radius of $0.10,0.15,0.20$, and $0.35 \mu \mathrm{m}$ for different retrieval scenarios. Using Mie theory, the extinction coefficient, the scattering coefficient, and the scattering phase function are calculated for a refractive index of $r=(1.427,0.000)$ at $756 \mathrm{~nm}$ (d'Almeida et al., 1991). Surface pressure and temperature profiles are taken from the three-hourly forecast of the European Centre for MediumRange Weather Forecasts (ECMWF) model, and have been interpolated to the SCIAMACHY overpass time and foot print (cf. http://www.knmi.nl/samenw/tosti/). The absorption cross sections of molecular oxygen are adopted from the Hitran 2008 data base (Rothman et al., 2009).

With the defined state vector $\boldsymbol{x}$ and the model parameter vector $\boldsymbol{b}$, Eq. (1) is inverted by combining a Gauß-Newton iteration with a linear least squares minimization for each iteration step,

$\hat{\boldsymbol{x}}_{\mathrm{lsq}}=\min _{x}|| \mathbf{S}_{y}^{-1 / 2}\left\{\tilde{\mathbf{y}}-\mathbf{K}_{\mathrm{ssc}} \boldsymbol{x}\right\} \|$ with $\tilde{\mathbf{y}}=\mathbf{y}-\boldsymbol{F}\left(\boldsymbol{x}_{\mathrm{o}}, \boldsymbol{b}\right)+\mathbf{K}_{\mathrm{ssc}} \boldsymbol{x}_{\mathrm{o}}$ and the measurement covariance matrix $\mathbf{S}_{y}$. Here, the forward model Jacobian is approximated by its single scattering contribution $\mathbf{K}_{\mathrm{ssc}}$ and $\boldsymbol{x}_{\mathrm{O}}$ is the solution of the previous iteration step. The solution of the inversion problem (2) can be expressed by

$\hat{\boldsymbol{x}}_{\mathrm{lsq}}=\mathbf{G} \tilde{\mathbf{y}}$

with the gain matrix $\mathbf{G}=\mathbf{K}^{\mathbf{T}} \mathbf{S}_{y}^{-1} \mathbf{K} \mathbf{K}^{T} \mathbf{S}_{y}^{-1}$. The statistical error on the solution $\hat{\boldsymbol{x}}_{1 \mathrm{sq}}$ due to the measurement noise, i.e. the retrieval noise is described by the covariance matrix

$\mathbf{S}_{x}=\mathbf{G S}_{y} \mathbf{G}^{T}$.

Convergence of the iteration is tested by comparing the $\chi^{2}$ values between measurement and simulation for two consecutive iteration steps $n-1$ and $n$. For a maximum number of nine iteration steps convergence is achieved when

$\left|\chi_{n}^{2}-\chi_{n-1}^{2}\right|<0.1 \chi_{n}^{2}$.

Otherwise data are rejected. A more stringent convergence criterion did not improve the quality of the retrieved aerosol profiles.

\section{Results}

\section{Retrieval over Libya}

To get a first indication on the performance of the proposed algorithm, we consider the retrieval of stratospheric aerosols over the Libyan desert. In Sect. 2, we mentioned the advantage of these measurements, i.e. the absence of tropospheric clouds, which eases the analysis of the retrieved data. Figure 6 shows the retrieved aerosol density at around 



Fig. 6. Stratospheric aerosol density retrieval over the Libyan desert. Dots indicate individual measurements while the solid line represents a one month running mean. (First panel) Aerosol density at $25 \mathrm{~km}$ retrieved from SCIAMACHY limb radiance measurements in the $\mathrm{O}_{2}$ A-band. (Second panel) Lambertian surface albedo retrieved at $500 \mathrm{~nm}$. (Third panel) Black sky albedo as a function of time due to its underlying dependence on solar zenith angle as proposed by Briegleb et al. (1986) (red dots) and Wang et al. (2005) (blue dots). (Fourth panel) SCIAMACHY limb radiance measurements at $500 \mathrm{~nm}$ at the tangent height closest to $25 \mathrm{~km}$ (blue) and forward simulations (red) using the retrieved aerosol profile and the fitted Lambertian surface albedo at $500 \mathrm{~nm}$. (Fifth panel) Relative differences between measurements and simulations. 
$25 \mathrm{~km}$ height, assuming a size of $0.35 \mu \mathrm{m}$ effective radius. The mean aerosol density is about 0.3 particles $\mathrm{cm}^{-3}$, which is a typical stratospheric background concentration at this altitude (e.g. Bingen et al., 2004b). Since the launch of SCIAMACHY, there has been no major volcanic eruption with significant stratospheric sulfur injection in the tropical and subtropical region and so, the mean retrieved values reflects the present stratospheric abundance. The time series shows a spread of the data around its monthly running value $\approx 0.1$ particles $\mathrm{cm}^{-3}$. This is significantly above the retrieval noise level $<0.01$ particles $\mathrm{cm}^{-3}$ at $25 \mathrm{~km}$ for a typical scattering angle between $40^{\circ}$ and $80^{\circ}$ for this geolocation (see the discussion of Fig. 11 later in the paper). For the time series in Fig. 6 the provided SCIAMACHY tangent height varies only by $\pm 100 \mathrm{~m}$. This means that the depicted time series shows measurements at slightly different altitudes and assuming the gradient in the aerosol density profile of Fig. 3 the corresponding fluctuation in the aerosol density is below $0.015 \mathrm{~cm}^{-3}$. In addition, the limb altitude pointing error of SCIAMACHY of a few hundred meters (von Savigny et al., 2005) is not sufficient to explain the spread of the aerosol density as shown in the figure. Thus we can rule out variations and errors of the tangent height to explain this feature. To our knowledge stratospheric aerosol at this altitude does not vary on these short time scales and so, we have to attribute this variation mainly to the effect of measurement biases and forward model errors on the retrieval.

To assess the spectral consistency of the retrieved aerosol properties, we look into the simulations of SCIAMACHY limb radiance measurements at $500 \mathrm{~nm}$ in the visible part of the solar spectrum. From these measurements, we determine a Lambertian surface albedo using a least squares inversion. In this manner, we account for the spectral variability of surface reflection between the visible and the spectral range of the $\mathrm{O}_{2}$ A-band. Moreover, for the radiance simulation the aerosol properties were used, which were retrieved beforehand from SCIAMACHY $\mathrm{O}_{2}$ A-band measurements. Figure 6 shows SCIAMACHY measurements and corresponding radiances simulation at $500 \mathrm{~nm}$. At this wavelength and for small scattering angles the limb radiance has significant sensitivity to stratospheric aerosol. In addition, the measurement is only little affected by ozone absorption at the Chappuis absorption band ranging from $440 \mathrm{~nm}$ to $1180 \mathrm{~nm}$. So uncertainties in the stratospheric ozone profile are of minor relevance in this context. The lowest two panels of Fig. 6 indicate a small underestimation of the measurement by the simulation of about $5 \%( \pm 5 \%)$. This is slightly larger than the spectral residuals of the aerosol fit in the $\mathrm{O}_{2}$ A-band (about $3 \%$ in the continuum). One possible explanation is the prior choice of aerosol micro-physical properties for the measurement simulations which is not fully suited to describe the correct wavelength dependence. Nevertheless, the retrieved vertical aerosol distribution improves significantly the SCIAMACHY limb measurement simulations in the visible. Keeping in mind that limb radiance measurements at the center of the Chappuis ozone band are used to retrieve ozone in the lower stratosphere (see e.g. von Savigny et al., 2003) the improved forward simulations may be beneficial for these retrievals.

The second panel of Fig. 6 shows the retrieved albedo at $500 \mathrm{~nm}$ with a clear seasonal dependence. During summer albedo values around 0.2 are retrieved, whereas during the winter season the retrieved albedo exceeds 0.6. The retrieved albedo is an effective parameter, accounting also for light scattering in the troposphere, which is not properly described in the retrieval. Nevertheless, the seasonal dependence can be attributed to bidirectional reflection at desert surfaces. The third panel of the figure shows a black sky albedo estimate of a desert surface as suggested by Wang et al. (2005) and Briegleb et al. (1986). The black sky albedo is defined as the albedo in the absence of a diffuse downward irradiance at the surface and is a function of solar zenith angle. Both parametrizations show the same seasonal dependence but with a smaller amplitude compared to the retrieved SCIAMACHY albedo. It is important to note that a direct comparison between the black sky albedo and the effective SCIAMACHY albedo is not valid. The SCIAMACHY albedo describes effectively the surface reflection into the upward directed solid angle which influences the limb radiances and which is difficult to estimate. In contrast, the black sky albedo accounts for reflection in the entire upward hemisphere. Nevertheless both albedos result from the same underlying bidirectional surface reflection, which is the origin of the observed seasonal albedo dependence in the figure.

Next, we estimate the effect of atmospheric emission at $761 \mathrm{~nm}$ on the aerosol retrieval. For this purpose we compare the measurements shown in Fig. 5 with measurement simulations using the SCIAMACHY viewing and solar geometry. For the simulation the aerosol density profile of Fig. 3 is utilized and an effective surface albedo is retrieved from the limb observations at 756 and $772 \mathrm{~nm}$. Subsequently, this albedo is used to simulate measurements at the center of the $\mathrm{O}_{2}$ A-band at $761 \mathrm{~nm}$. The difference between measurement and simulation at $70 \mathrm{~km}$ is employed as a conservative estimate of the atmospheric emission because at this altitude the effect of aerosols on the measurement can be neglected. Using the volume emission rate of the $\mathrm{O}_{2} \mathrm{~A}$ band for a typical dayglow situation (adapted from Fig. 5 of Buchholtz et al., 1986) we extrapolated the emission signal from $70 \mathrm{~km}$ to the altitude range from $0-40 \mathrm{~km}$ used by the retrieval. The emission signal is shown in Fig. 7 with a clear maximum at $45 \mathrm{~km}$ due to the production of $\mathrm{O}_{2}\left({ }^{1} \Sigma\right)$ by ozone photodissociation followed by a quenching of $\mathrm{O}\left({ }^{1} \mathrm{D}\right)$. The remaining emission below $30 \mathrm{~km}$ corresponds to $\mathrm{O}_{2}\left({ }^{1} \Sigma\right)$ production by resonance scattering in the $\mathrm{O}_{2} \mathrm{~A}$ band. Here we intrinsically assume that the emission signal is determined predominantly from atmospheric emission close to the tangent height and so atmospheric emission at higher altitudes along the instrument line-of-sight is ignored. This approach may result in an underestimation at lower tangent height, and so the derived 

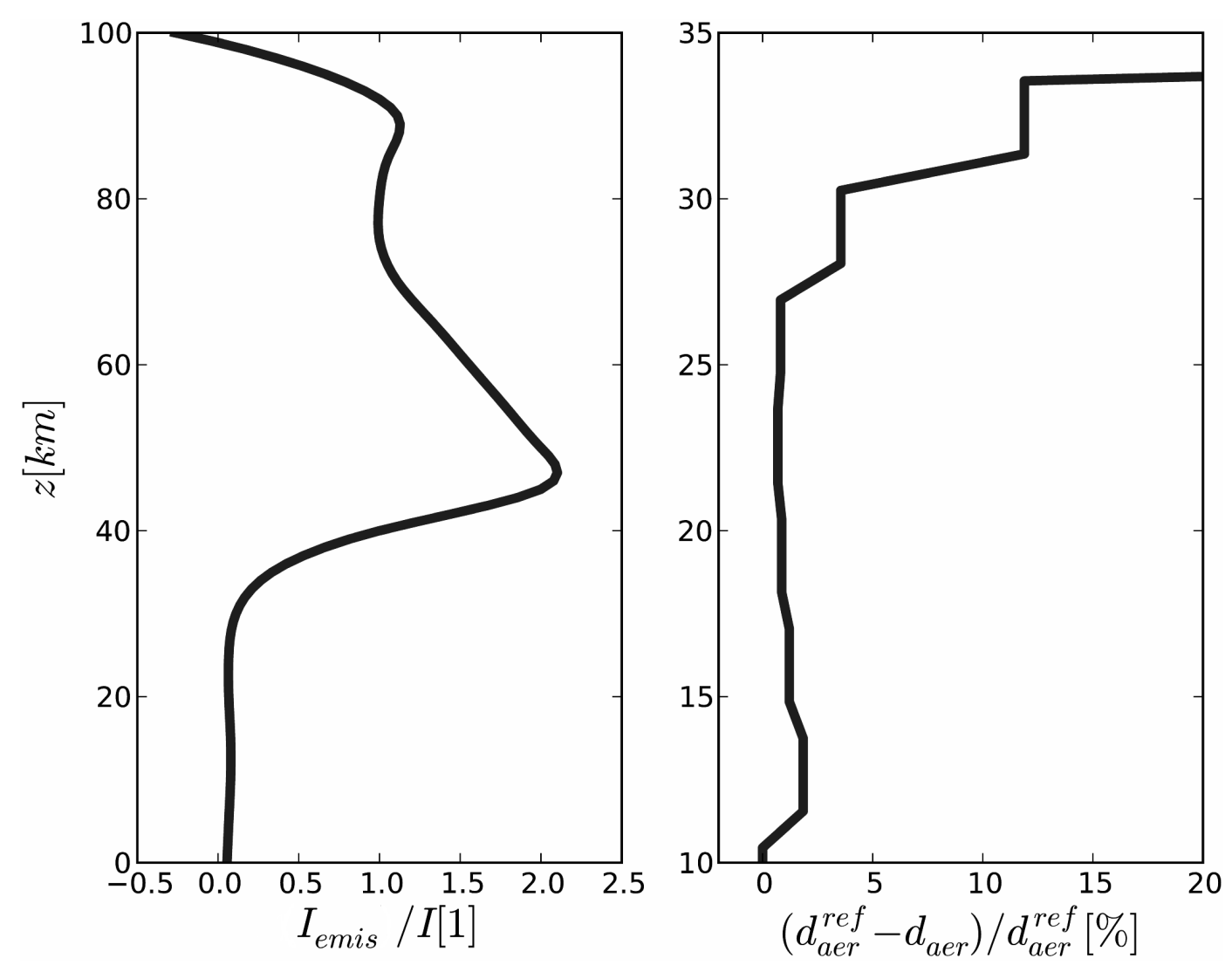

Fig. 7. (left panel) Relative contribution of the emission signal $I_{\mathrm{emis}}$ to a SCIAMACHY limb radiance measurements for a representative retrieval over the Libyan Desert. The emission signal is estimated as described in Sect. 4. (right panel) Effect on the aerosol retrieval when atmospheric emission is neglected in the retrieval. Here, $d_{\mathrm{aer}}^{\mathrm{ref}}$ is the retrieved aerosol density when emission is added to the measurement simulations and $d_{\text {aer }}$ is the retrieved aerosol density when emission is ignored.

emission signal should only be considered as a rough estimate. Finally, we compare a typical retrieval from SCIAMACHY measurements when the emission signal is added to the forwards simulation of a corresponding retrieval with the retrieval performance when the emission signal is omitted. The right panel of Fig. 7 depicts the effect on the retrieved aerosol profile which is $<5 \%$ for altitudes below $30 \mathrm{~km}$.

These first results for SCIAMACHY measurements over the Libyan desert provide confidence in the overall retrieval approach. To get a more quantitative estimate of the retrieval accuracy, a comparison of our retrieval with independent spatially and temporally co-located measurements of stratospheric aerosol is needed.

\section{Comparison with SAGE II}

SAGE II provides aerosol density and radius profiles which are retrieved from solar occultation at several wavelengths. For our study, we employ version 6.2 of the SAGE data product, which are provided by the NASA atmospheric science data center (c.f. http://eosweb.larc.nasa.gov). To compare SAGE II data with the SCIAMACHY aerosol particle density profiles, it is important to realize that the SCIAMACHY product depends on the a prior choice of the aerosol size parameter. Thus we convert both, the SAGE II and the SCIAMACHY aerosol profiles to extinction profiles at a certain wavelength using the corresponding micro-physical aerosol properties of the retrieval. Furthermore we consider only SAGE and SCIAMACHY aerosol profiles, which are spatially co-located within $\pm 300 \mathrm{~km}$ along flight direction and $\pm 115 \mathrm{~km}$ across flight direction, and with a measurement time difference of less than $12 \mathrm{~h}$. Figure 8 shows one specific SAGE II and SCIAMACHY aerosol extinction profile at $525 \mathrm{~nm}$ over central China. Both profiles show a maximum aerosol extinction of $3 \cdot 10^{-4} \mathrm{~km}^{-1}$ between 15 and $18 \mathrm{~km}$. Below $12 \mathrm{~km}$ the SCIAMACHY extinction is much larger than the corresponding SAGE extinction. At these altitudes, contamination of the line of sight by thin cirrus clouds may cause the large difference between the two profiles, which does not necessarily indicate an error in one of the retrievals. Above the stratospheric maximum the SAGE profile decays more rapidly and for this case no stratospheric aerosol are reported above $25 \mathrm{~km}$. The SCIAMACHY profile decreases less rapidly towards higher altitudes and non-zero values are found up to $30 \mathrm{~km}$. 


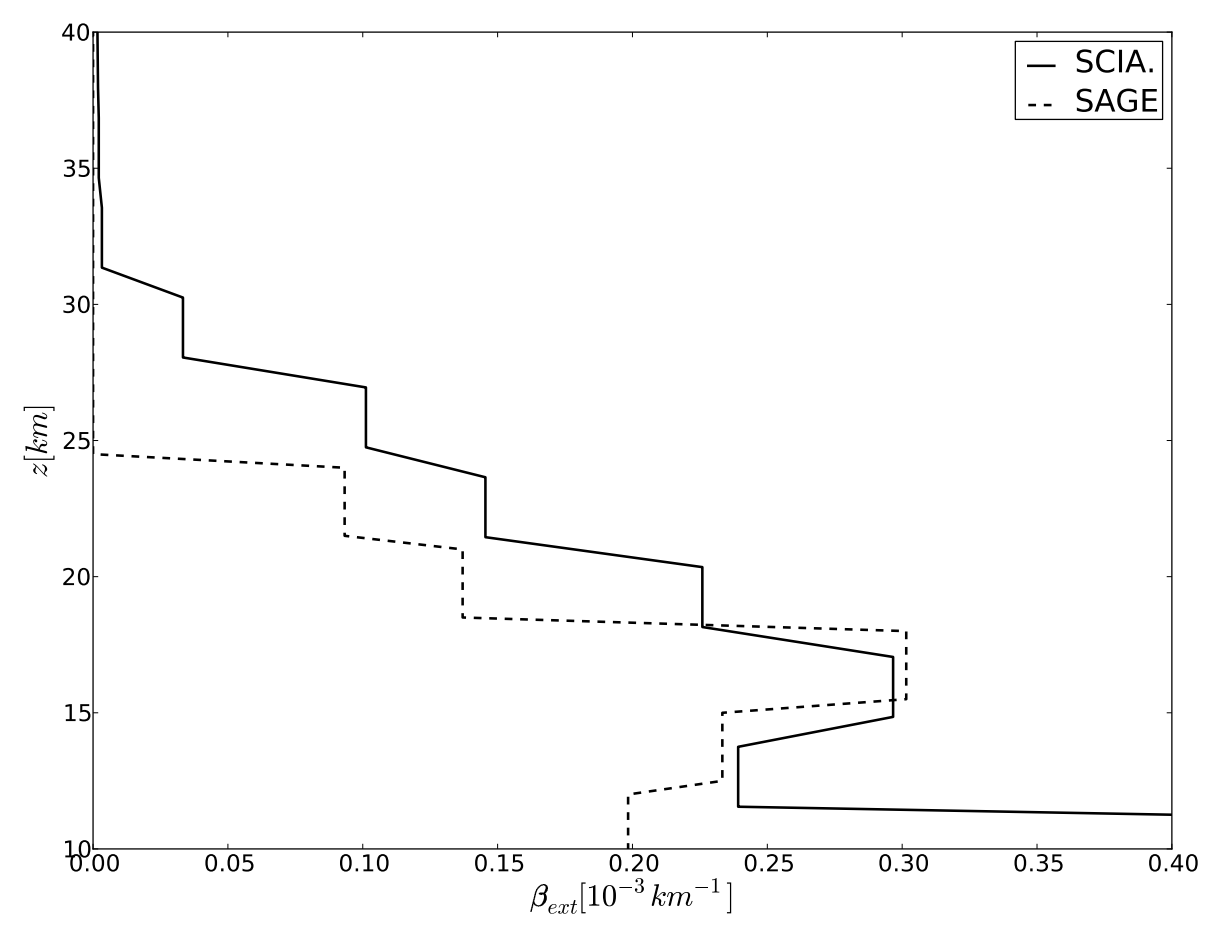

Fig. 8. Spatially and temporally co-located SAGE II and SCIAMACHY aerosol extinction profile at 525 nm above China, 3 January 2003. The SAGE II extinction profile are calculated from SAGE II aerosol density and radius profiles. The SCIAMACHY extinction profile is determined in the same way.

For a more extended comparison, we consider about 2000 co-locations between SAGE II and SCIAMACHY measurements for the period January 2003 to June 2005, between $75^{\circ}$ southern and northern latitude. Figure 9 shows a scattering diagram of co-located SAGE II and SCIAMACHY aerosol extinction coefficients in a $3 \mathrm{~km}$ thick layer centered at $25 \mathrm{~km}$. For comparison the SAGE profiles are interpolated linearly to the SCIAMACHY retrieval heights. For a mean radius $\bar{r}=0.35 \mu \mathrm{m}$, the SCIAMACHY aerosol extinctions exceed significantly the corresponding SAGE values. This is illustrated by a linear regression through the data points where the fitted line is constrained to go through the origin. For $\bar{r}=0.35 \mu \mathrm{m}$, we obtain a slope of $m=0.6$ which deviates significantly from the ideal 1-to-1 line. The spread of the data set can be characterized by the mean difference $\delta_{m}=1.5 \cdot 10^{-5} \mathrm{~km}^{-1}$ between the data points and the linear regression.

Figure 10 illustrates the difference between SAGE and SCIAMACHY aerosol extinctions as a function of the scattering angle and latitude of the SCIAMACHY observation. Because of the sun-synchronized orbit of ENVISAT, scattering angle and latitude are correlated. The figure illustrates that differences between SAGE and SCIAMACHY retrievals are smallest at northern mid-latitudes or for smaller scattering angle. For these cases, the aerosol sensitivity of the measurements is largest and hence forward model errors, e.g. due to a wrong prior estimate of the aerosol size, have a smaller effect on the retrieval than for larger scattering angle. The reduced aerosol sensitivity of the measurement for large scattering angles is also the reason for the little number of successful SCIAMACHY retrievals at the Southern Hemisphere, respectively at larger scattering angles. Figures 9 and 10 also present SCIAMACHY retrieval results for smaller aerosol particles with a mean radius of $0.15 \mu \mathrm{m}$. Here, the correlation between SCIAMACHY and SAGE II is clearly improved with a slope of the linear data regression of $m=1.1$ but with a small effect on the spread with $\delta_{m}=1.3 \cdot 10^{-5} \mathrm{~km}^{-1}$. For the smaller aerosols much more retrievals converge for measurements over the Southern Hemisphere and the relative difference between both data sets depends less on scattering angle or latitude, respectively. This indicates a better choice of the prior aerosol size and a clear improvement with respect to the previous retrieval.

To assess the data spread in Fig. 10, we investigate the retrieval noise for a set of simulated measurements covering the scattering angles of Fig. 10. The measurement noise is estimated by an instrument noise model. For this purpose we consider limb radiances $I(z, \lambda)$ as a function of tangent height $z$ and wavelength $\lambda$ in the $\mathrm{O}_{2}$ A-band. The corresponding photosignal $S_{\mathrm{ph}}(\lambda)$, i.e. the number of counted electrons, is given by

$S_{\mathrm{ph}}(z, \lambda)=c_{\mathrm{ph}} I(z, \lambda)$

with a calibration constant $c_{\text {ph }}$. The instrument noise model 


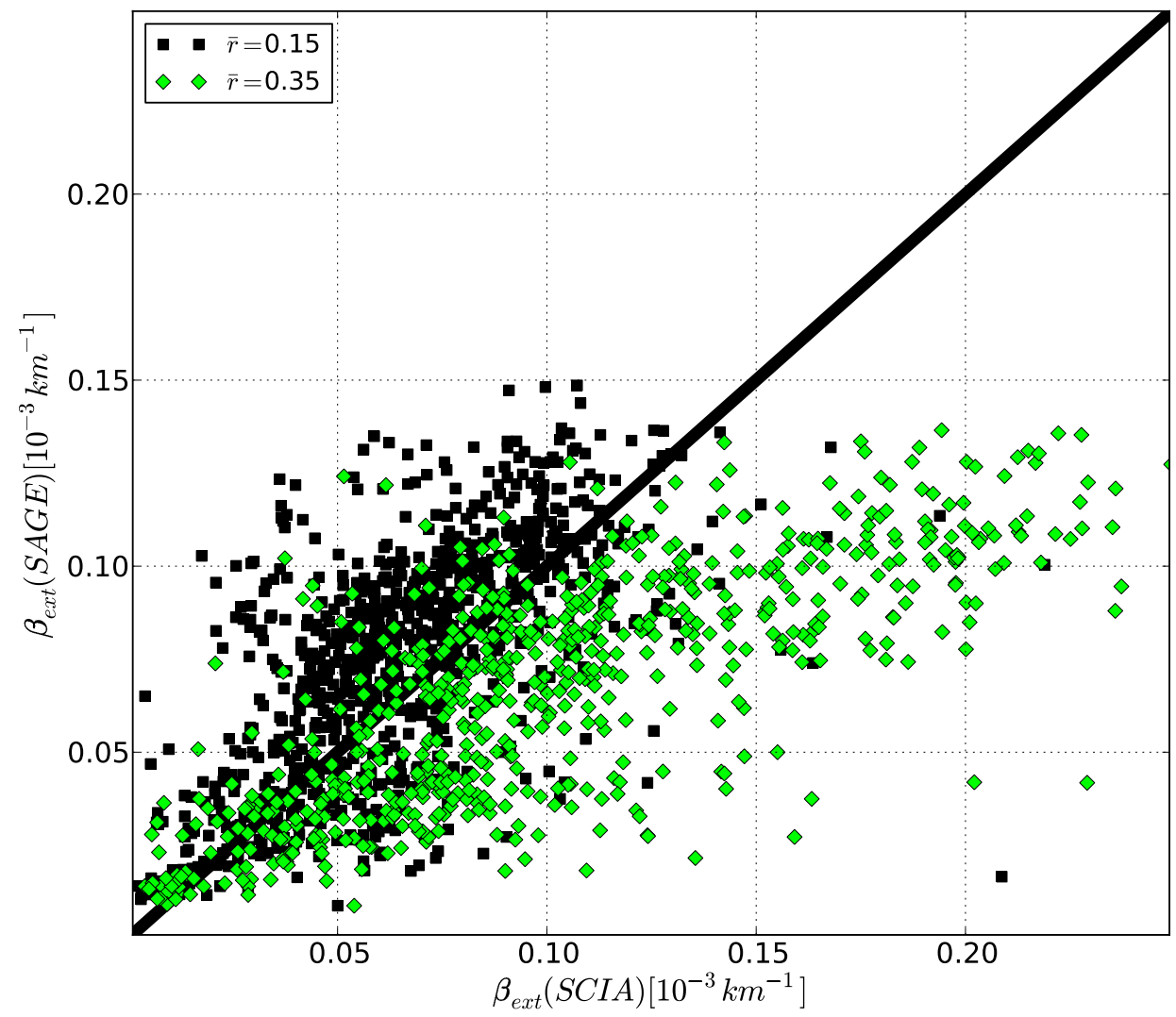

Fig. 9. Scatter diagram of co-located SAGE II and SCIAMACHY aerosol extinction coefficient at $25 \mathrm{~km}$. The black squares indicate SCIAMACHY retrieval with a mean radius $\bar{r}=0.15 \mu \mathrm{m}$, the green diamonds shows retrieval with $\bar{r}=0.35 \mu \mathrm{m}$.

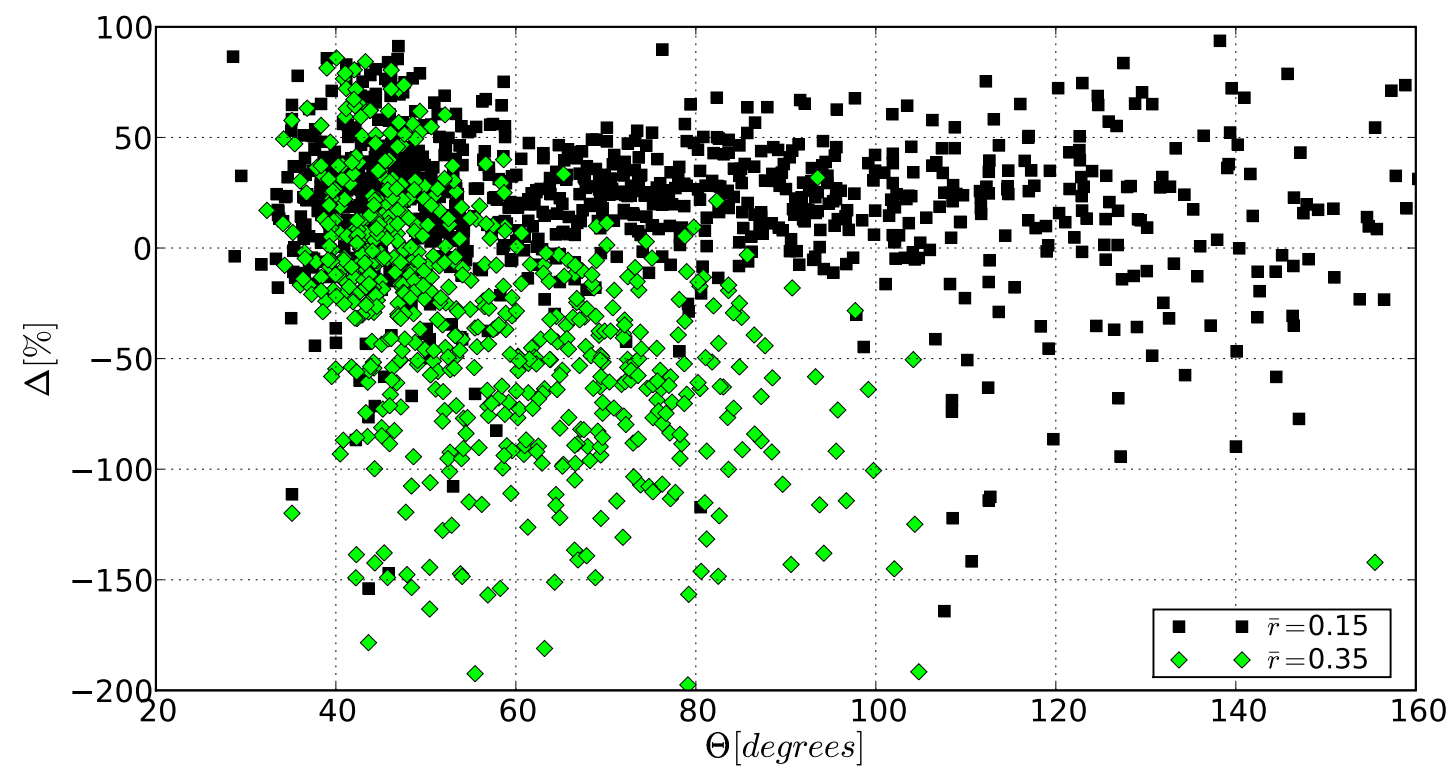

Fig. 10. Relative difference between SAGE and SCIAMACHY aerosol extinction coefficients, $\Delta=(\mathrm{SAGE}-\mathrm{SCIAMACHY}) / \mathrm{SAGE}$, at $25 \mathrm{~km}$ as a function of scattering angle $\Theta$. The black squares indicate SCIAMACHY retrievals with a mean radius $\bar{r}=0.15 \mu \mathrm{m}$, the green diamonds shows retrievals with $\bar{r}=0.35 \mu \mathrm{m}$. 


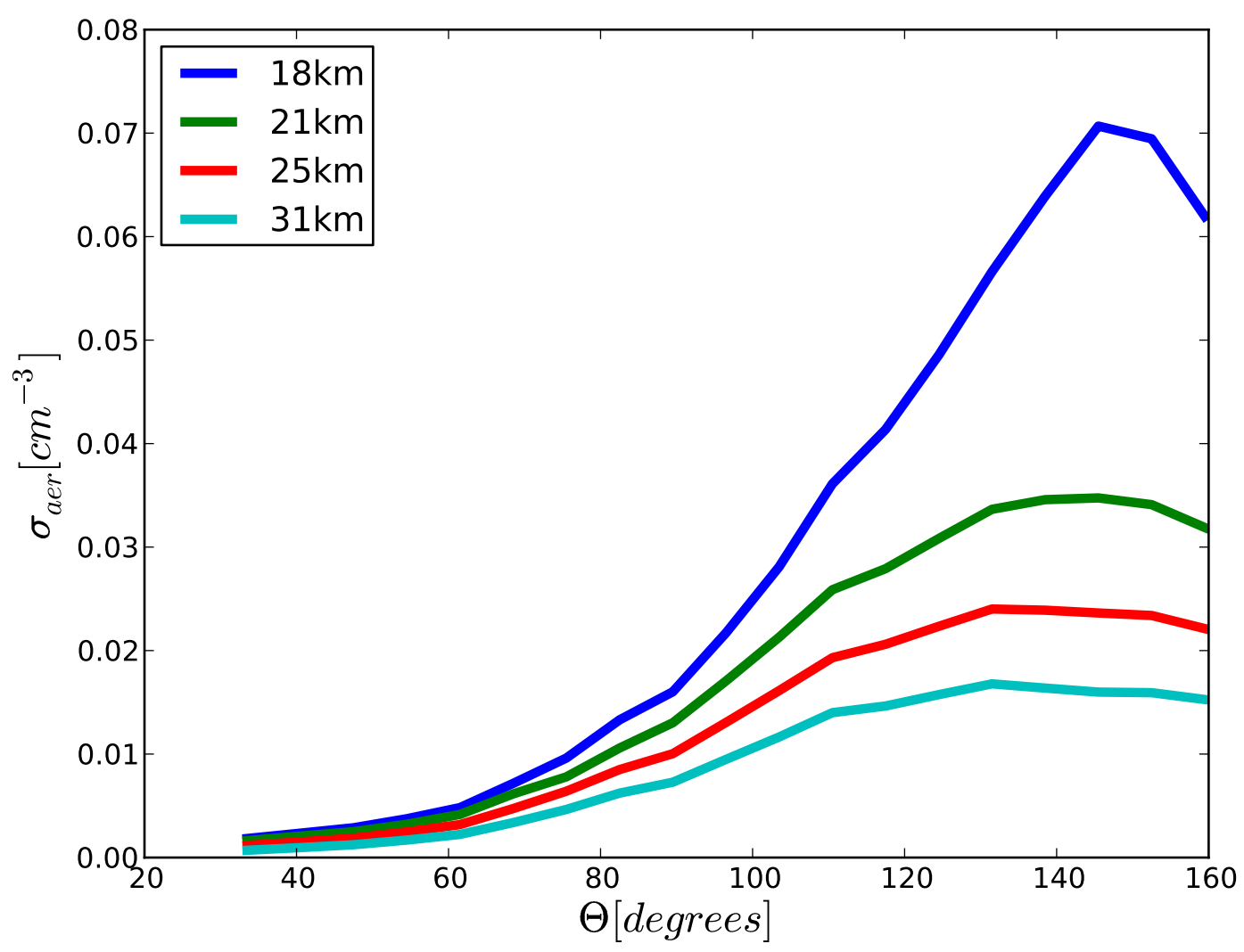

Fig. 11. Retrieval noise as function of scattering angle $\theta$ at four different heights $18,21,25$ and $31 \mathrm{~km}$. The retrieval noise is estimated for simulated measurements using the SCIAMACHY noise model in Eq. (7). The measurements are simulated for a low surface albedo of $5 \%$.

combines the shot noise contribution $\sqrt{S_{\text {ph }}}$ and the instrument noise $N_{\text {inst }}$. The latter combines error sources, like detector read-out noise and digitization noise, which do not depend on the signal strength. Thus, we obtain the signal to noise ratio of the measurement by

$\operatorname{SNR}(z, \lambda)=\frac{c_{\mathrm{ph}} I(z, \lambda)}{\sqrt{c_{\mathrm{ph}} I(z, \lambda)+N_{\text {inst }}^{2}}}$.

Both, the calibration constant $c_{\mathrm{ph}}$ and the instrument noise $N_{\mathrm{i}}$ are determined from the measurement noise of a representative SCIAMACHY limb scan over the Libyan Desert. The error model is tested for the set of SCIAMACHY measurements which are used in Fig. 10 covering the range of scattering angles $30-160^{\circ}$. Here, the measurement error could be described with an accuracy of $\leq 15 \%$ of the absolute measurement error at tangent heights $\leq 30 \mathrm{~km}$.

For the retrieval noise estimate in Fig. 11, measurements are simulated for a low surface albedo of $5 \%$ and for the aerosol profile in Fig. 3. Due to the low albedo the noise estimate can be considered as an upper threshold. The retrieval noise is shown for four different heights 18, 21, 25 and $31 \mathrm{~km}$. It increases with increasing scattering angle $\theta$ with a maximum at $\theta=150^{\circ}$. The increase in the retrieval noise is due to a decrease in the aerosol sensitivity of the measurements. For scattering angles $\theta>150^{\circ}$ the aerosol sensitivity of the measurements increases because of the backward scattering peak of the aerosol scattering phase function. Overall, at 18,21 and $25 \mathrm{~km}$ the retrieval noise stays below $0.075,0.035$ and $0.025 \mathrm{~cm}^{-3}$ which correspond to retrieval retrieval errors below $4,3.5$ and $6 \%$. At $31 \mathrm{~km}$ altitude the retrieval noise does not exceed $0.07 \mathrm{~cm}^{-3}$ or $25 \%$. So, the data spread in Fig. 10, especially at small scattering angle, cannot be caused by the SCIAMACHY retrieval noise. In contrast, the SAGE II data uncertainty for the considered data set at $25 \mathrm{~km}$ altitude is in the order of $20 \%$, which, at least partly, explains the scattering of data in Fig. 10.

To illustrate the overall retrieval performance, Fig. 12 shows the slope $m$ and the deviation $\delta_{m}$ as a function of height for different aerosol effective radii of $\bar{r}=0.10,0.15$, 0.25 , and $0.35 \mu \mathrm{m}$. The figure indicates that for $\bar{r} \approx 0.20 \mu \mathrm{m}$ the best correlation can be achieved. For this radius and above $14 \mathrm{~km}$ altitude, a small height dependence of $m$ is present, which may indicate a small increase of the aerosol height at lower altitude. The effect of aerosol size on the deviation $\delta_{m}$ is less pronounced. For $\bar{r}=0.20 \mu \mathrm{m}, \delta_{m}$ varies from $25 \%$ of the mean SAGE extinction to $<15 \%$ at $22 \mathrm{~km}$. For $\bar{r}=0.10$ and $0.35 \mu \mathrm{m}$, the deviation is somewhat larger. At lower altitudes $<14 \mathrm{~km}$, the deviation $\delta_{m}$ increases, which 

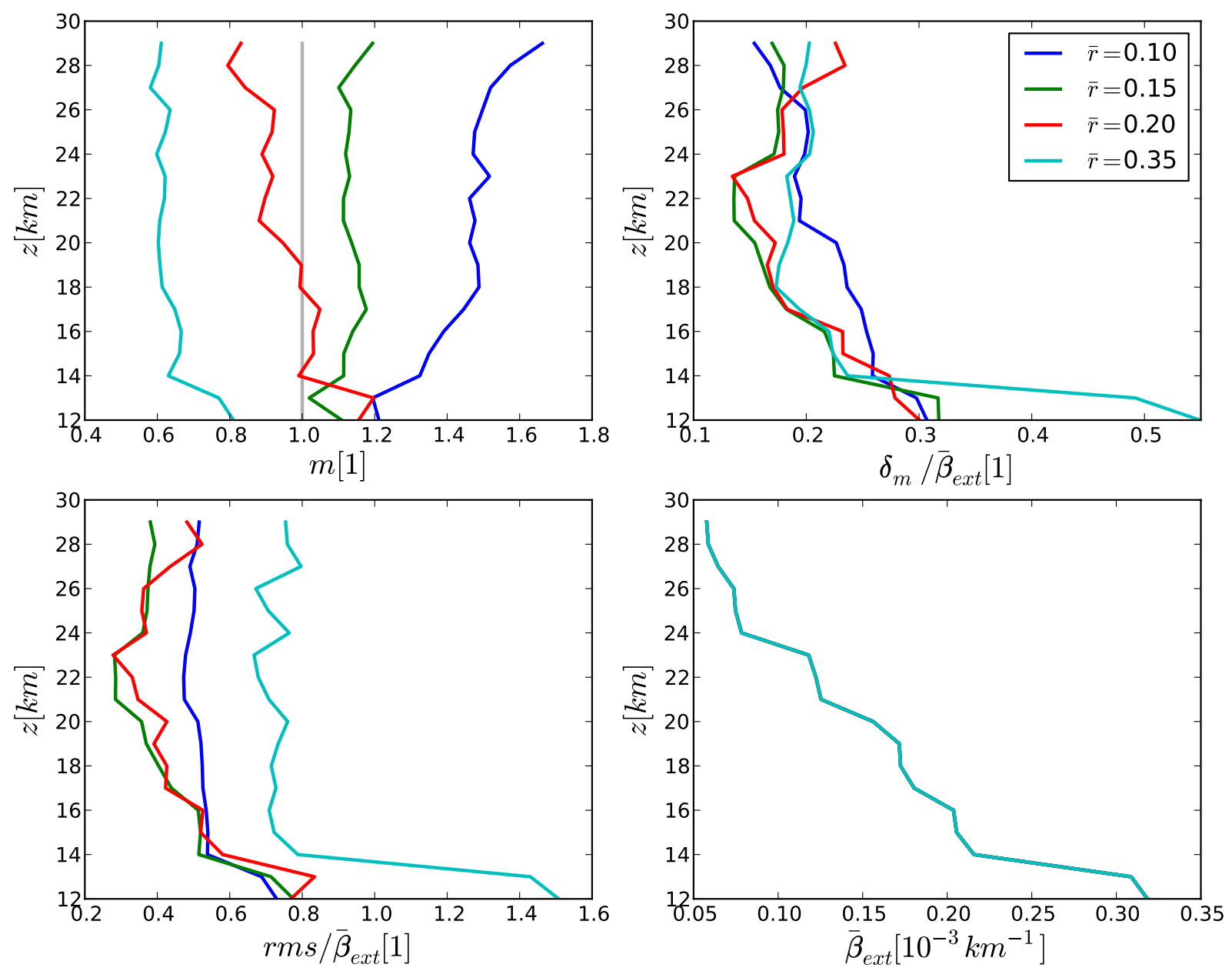

Fig. 12. (Upper left panel) Slope of a linear regression for a scattering diagram as in Fig. 9 as a function of height $z$. (Upper right panel) Mean deviation from the linear regression $\delta_{m}$ as a function of altitude $z$, relative to the mean SAGE extinction profile $\bar{\beta}_{\text {ext }}$ (Lower left panel) Root mean square difference between SCIAMACHY and SAGE relative to $\bar{\beta}_{\text {ext }}$. (Lower right panel) Mean SAGE extinction profile $\bar{\beta}_{\text {ext }}$.

may be caused by the presences of cirrus clouds. Overall the agreement between the SAGE II data product and the presented retrievals is in the order of 30-50\% root mean square difference relative to the mean SAGE profile, with a minimum of $30 \%$ around $22 \mathrm{~km}$. The comparison of various stratospheric aerosol products from different instruments by Thomason and Peter (2006) indicates differences between $20-60 \%$ and so the differences between SAGE and SCIAMACHY aerosol extinction of this study are in agreement with these findings.

Overall, bearing in mind that the investigated data set describes the current stratospheric background aerosol with low particle densities, the achieved agreement between the SAGE II and SCIAMACHY aerosol retrieval not only underlines the suitability of the retrieval concept, but also shows a satisfying quality of the SCIAMACHY retrieval product.

\section{Conclusions}

In this study, we have presented an approach to retrieve stratospheric aerosol density profiles from SCIAMACHY limb radiance measurements in the spectral range of the $\mathrm{O}_{2}$ A absorption band around $760 \mathrm{~nm}$. The different paths of the measured light at the spectral continuum with very little atmospheric absorption and at the center of the $\mathrm{O}_{2}$ absorption band with strong atmospheric absorption allows to disentangle the effect of surface reflection and aerosol scattering on the measurement. Using an iterative least squares minimization, aerosol density profiles are retrieved in the height range $10-40 \mathrm{~km}$. Retrieval simulations for measurements over the Libyan desert with very little cloud contamination showed the capability to determine surface reflection properties and aerosol density profiles. To verify the retrieval quality, about 2000 SCIAMACHY aerosol density profiles were compared with SAGE II aerosol extinction retrievals for the period 2003-2005. For this purpose the SCIAMACHY 
profiles between $75^{\circ}$ southern and northern latitudes were converted to extinction profiles at $525 \mathrm{~nm}$ and so, they could be compared with corresponding SAGE extinction profiles.

Overall, for background stratospheric aerosol concentrations with low particle densities the SAGE II and SCIAMACHY extinction profiles differ by less than $50 \%$ root mean square difference relative to the mean SAGE profile in the altitude range $14-30 \mathrm{~km}$ with a best agreement of $30 \%$ around $22 \mathrm{~km}$. The SCIAMACHY retrieval performance depends critically on the prior knowledge of the aerosol size. This information cannot be retrieved from the SCIAMACHY $\mathrm{O}_{2}$ A-band measurements, and so an a priori choice had to be made. Here, the best agreement between SAGE and SCIAMACHY retrievals could be achieved for an aerosol effective size radius of $\bar{r}=0.20 \mu \mathrm{m}$. Due to the different scattering geometry, the SCIAMACHY retrieval performance differs as a function of latitude and aerosol size. At southern latitudes, and so for larger scattering angles of the limb single scattering geometry, the aerosol sensitivity of the measurement is small. Therefore, the SCIAMACHY retrieval is more sensitive to forward model errors and measurement biases. In turn, only for the smaller aerosol sizes a good convergence performance of the retrieval could be achieved for both the Northern and Southern Hemispheres.

The SCIAMACHY aerosol product can be beneficial for other SCIAMACHY limb retrieval products such as stratospheric ozone profile retrieval because of a more accurate forward simulation of the limb radiance measurements. Moreover, the SCIAMACHY aerosol abundances in combination with stratospheric ozone and nitrogen oxide profiles, both retrieved from SCIAMACHY measurements, represents a unique data set of spatially and temporally co-located measurements with a global coverage within 6 days. In the future this data may be useful to improve our knowledge on the long-term chemical evolution of the stratosphere. Nevertheless, further effort is needed for exploiting the full capability of SCIAMACHY limb measurements for stratospheric aerosol retrieval. For example, limb radiance measurements at other wavelengths may provide useful information on the size of stratospheric aerosol. Furthermore, forward model and measurement errors, e.g. due to the polarization sensitivity of the measurement in the spectral range of strong atmospheric absorption, must be reduced to fully exploit SCIAMACHY limb radiance measurements at all latitudes.

Acknowledgements. This research was funded by the Netherlands Space Office under the project SCIAVISIE. We thank Christian van Savigny, Institute of Environmental Physics (IUP), Bremen, for open and stimulating discussions on the subject of this paper.

Edited by: E. Kyrölä

\section{References}

Bernath, P. F., McElroy, C. T., Abrams, M. C., Boone, C. D., Butler, M., Camy-Peyret, C., Carleer, M., Clerbaux, C., Coheur, P., Colin, R., DeCola, P., DeMazière, M., Drummond, J. R., Dufour, D., Evans, W. F. J., Fast, H., Fussen, D., Gilbert, K., Jennings, D. E., Llewellyn, E. J., Lowe, R. P., Mahieu, E., McConnell, J. C., McHugh, M., McLeod, S. D., Michaud, R., Midwinter, C., Nassar, R., Nichitiu, F., Nowlan, C., Rinsland, C. P., Rochon, Y. J., Rowlands, N., Semeniuk, K., Simon, P., Skelton, R., Sloan, J. J., Soucy, M., Strong, K., Tremblay, P., Turnbull, D., Walker, K. A., Walkty, I., Wardle, D. A., Wehrle, V., Zander, R., and Zou, J.: Atmospheric Chemistry Experiment (ACE): Mission overview, Geophys. Res. Lett., 32, L15S01, doi:10.1029/2005GL022386, 2005.

Bingen, C., Fussen, D., and Vanhellemont, F.: A global climatology of stratospheric aerosol size distribution parameters derived from SAGE II data over the period 1984-2000: 2. Reference data, J. Geophys. Res., 109, D06202, doi:10.1029/2003JD003511, 2004a.

Bingen, C., Fussen, D., and Vanhellemont, F.: A global climatology of stratospheric aerosol size distribution parameters derived from SAGE II data over the period 1984-2000: 1. Methodology and climatological observations, J. Geophys. Res., 109, D06201, doi:10.1029/2003JD003518, 2004b.

Bourassa, A. E., Degenstein, D. A., Gattinger, R. L., and Llewellyn, E. J.: Stratospheric aerosol retrieval with optical spectrograph and infrared imaging system limb scatter measurements, J. Geophys. Res., 112, D10217, doi:10.1029/2006JD008079, 2007.

Bovensmann, H., Burrows, J. P., Buchwitz, M., Frerick, J., Noël, S., Rozanov, V. V., Chance, K. V., and Goede, A. P. H.: SCIAMACHY: Mission Objectives and Measurement Modes, J. Atmos. Sci., 56, 127-150, 1999.

Briegleb, B. P., Minnis, P., Ramanathan, V., and Harrison, E.: Comparison of Regional Clear-Sky Albedos Inferred from Satellite Observations and Model Computations., J. Appl. Meteorol., 25, 214-226, 1986.

Buchholtz, A., Skinner, W., Abreu, V., and Hays, P.: The dayglow of the $\mathrm{O}_{2}$ atmospheric band system, Planet Space Sci., 34, 1031$1035,1986$.

Chu, W. P., Trepte, C. R., Veiga, R. E., Cisewski, M. S., and Taha, G.: SAGE III measurements, in: Society of Photo-Optical Instrumentation Engineers (SPIE) Conference Series, edited by: Barnes, W. L., 4814, 453-460, 2002.

Crutzen, P. J.: The influence of nitrogen oxides on the atmospheric ozone content, Q. J.e Roy. Meteorol. Soc., 96, 320-325, doi:10.1002/qj.49709640815, 1970.

Crutzen, P. J.: The possible importance of CSO for the sulfate layer of the stratosphere, Geophys. Res. Lett., 3, 73-76, doi:10.1029/GL003i002p00073, 1976.

d'Almeida, G., Koepke, P., and Shettle, E.: Atmospheric Aerosols, Global Climatology and Radiative Characteristics, A. DEEPAK Publishing, Hampton, Virginia USA, 1991.

Deshler, T., Hofmann, D. J., Johnson, B. J., and Rozier, W. R.: Balloonborne measurements of the Pinatubo aerosolsize distribution and volatility at Laramie, Wyoming during the summer of 1991, Geophys. Res. Lett., 19, 199-202, doi:10.1029/91GL02787, 1992.

Deshler, T., Johnson, B. J., and Rozier, W. R.: Balloonborne measurements of Pinatubo aerosol during 1991 and 1992 at $41^{\circ} \mathrm{N}-$ 
Vertical profiles, size distribution, and volatility, Geophys. Res. Lett., 20, 1435-1438, doi:10.1029/93GL01337, 1993.

Fahey, D. W., Kawa, S. R., Woodbridge, E. L., Tin, P., Wilson, J. C., Jonsson, H. H., Dye, J. E., Baumgardner, D., Borrmann, S., and Toohey, D. W.: In situ measurements constraining the role of sulphate aerosols in mid-latitude ozone depletion, Nature, 363, 509-514, 1993.

Hofmann, D. J. and Rosen, J. M.: Stratospheric sulfuric acid fraction and mass estimate for the 1982 volcanic eruption of El Chichon, Geophys. Res. Lett., 10, 313-316, doi:10.1029/GL010i004p00313, 1983.

Hofmann, D., Barnes, J., O’Neill, M., and Trudeau, M.: Increase in background stratospheric aerosol observed with lidar at Mauna Loa Observatory and Boulder, Colorado, Geophys. Res. Lett., 36, L15808, doi:10.1029/2009GL039008, 2009.

Junge, C. E. and Manson, J. E.: Stratospheric Aerosol Studies, J. Geophys. Res., 66, 2163-2182, doi:10.1029/JZ066i007p02163, 1961.

Kärcher, B. and Ström, J.: The roles of dynamical variability and aerosols in cirrus cloud formation, Atmos. Chem. Phys., 3, 823838, doi:10.5194/acp-3-823-2003, 2003.

Loughman, R. P., Griffioen, E., Oikarinen, L., Postylyakov, O. V., Rozanov, A., Flittner, D. E., and Rault, D. F.: Comparison of radiative transfer models for limb-viewing scattered sunlight measurements, J. Geophys. Res., 109, D06303, doi:10.1029/2003JD003854, 2004.

Mauldin, L. E., Zaun, N. H., Cormick Jr., M. P., Guy, J. H., and Vaughn, W. R.: Stratospheric Aerosol and Gas Experiment II Instrument: A functional description, Opt. Eng., 24, 307-312, 1985.

McCormick, M. P., Chu, W. P., McMaster, L. R., Hamill, P., Swissler, T. J., and Pepin, T. J.: Satellite studies of the stratospheric aerosol, B. Am. Meteorol. Soc., 60, 1038-1046, 1979.

McCormick, M. P., Steele, H. M., Hamill, P., Chu, W. P., and Swissler, T. J.: Polar Stratospheric Cloud Sightings by SAM II., J. Atmos. Sci., 39, 1387-1397, 1982.

McCormick, M. P., Thomason, L. W., and Trepte, C. R.: Atmospheric effects of the Mt Pinatubo eruption, Nature, 373, 399404, doi:10.1038/373399a0, 1995.

Mugnai, A., Fiocco, G., and Grams, G.: Effects of aerosol optical properties and size distributions on heating rates induced by stratospheric aerosols, Q. J. Roy. Meteorol. Soc., 104, 783-796, 1978.

Oberreck, V., Danielsen, E., Snetsinger, K., Ferry, G., Fong, W., and Hayes, D.: Effect of the eruption of El Chichon on stratospheric aerosol size and compostion, Geophys. Res. Lett., 10, 1021-1024, 1983.

Penner, J. E., Chen, Y., Wang, M., and Liu, X.: Possible influence of anthropogenic aerosols on cirrus clouds and anthropogenic forcing, Atmos. Chem. Phys., 9, 879-896, doi:10.5194/acp-9-8792009, 2009.

Rossow, W. and Schiffer, R.: Advances in understanding clouds from ISCCP, B. Am. Meteorol. Soc., 80, 2261-2287, 1999.
Rothman, L. S., Gordon, I. E., Barbe, A., Benner, D. C., Bernath, P. F., Birk, M., Boudon, V., Brown, L. R., Campargue, A., Champion, J., Chance, K., Coudert, L. H., Dana, V., Devi, V. M., Fally, S., Flaud, J., Gamache, R. R., Goldman, A., Jacquemart, D., Kleiner, I., Lacome, N., Lafferty, W. J., Mandin, J., Massie, S. T., Mikhailenko, S. N., Miller, C. E., Moazzen-Ahmadi, N., Naumenko, O. V., Nikitin, A. V., Orphal, J., Perevalov, V. I., Perrin, A., Predoi-Cross, A., Rinsland, C. P., Rotger, M., Šimečková, M., Smith, M. A. H., Sung, K., Tashkun, S. A., Tennyson, J., Toth, R. A., Vandaele, A. C., and Vander Auwera, J.: The HITRAN 2008 molecular spectroscopic database, J. Quant. Spectrosc. Radiat. Transfer, 110, 533-572, 2009.

Saitoh, N., Hayashida, S., Sugita, T., Nakajima, H., Yokota, T., Hayashi, M., Shiraishi, K., Kanzawa, H., Ejiri, M. K., Irie, H., Tanaka, T., Terao, Y., Bevilacqua, R. M., Randall, C. E., Thomason, L. W., Taha, G., Kobayashi, H., and Sasano, Y.: Intercomparison of ILAS-II version 1.4 aerosol extinction coefficient at $780 \mathrm{~nm}$ with SAGE II, SAGE III, and POAM III, J. Geophys. Res., 111, D11S05, doi:10.1029/2005JD006315, 2006.

Slanger, T. and Copeland, R.: Energetic Oxygen in the upper atmosphere and the laboratory, Chem. Rev., 103, 4731-4765, 2003.

Solomon, S.: Stratospheric ozone depletion: A review of concepts and history, Rev. Geophys., 37, 275-316, doi:10.1029/1999RG900008, 1999.

Taha, G., Rault, D. F., Loughman, R. P., Bourassa, A. E., and von Savigny, C.: SCIAMACHY stratospheric aerosol extinction profile retrieval using the OMPS/LP algorithm, Atmos. Meas. Tech., 4, 547-556, doi:10.5194/amt-4-547-2011, 2011.

Thomason, L. and Peter, T.: Assessment of Stratospheric Aerosol Properties (ASAP), SPARC Report No. 4 WCRP-124, WMO/TD-No. 1295, available online at: http://www.atmosp. physics.ca/SPARC/, 2006.

von Savigny, C., Haley, S., Sioris, C., McDade, I., Llewellyn, E., Degenstein, D., Evans, W., Gattinger, R., Griffioen, E., Kyrölä, E., Lloyd, N., McConnell, J., McLinden, C., Mégie, G., Murtagh, D., Solheim, B., and Strong, K.: Stratospheric ozone profiles retrieved from limb scattered sunlight radiance spectra measured by the OSIRIS instrument on the Odin satellite, Geophys. Res. Lett., 30, 1755, doi:10.1029/2002GL016401, 2003.

von Savigny, C., Kaiser, J. W., Bovensmann, H., Burrows, J. P., McDermid, I. S., and Leblanc, T.: Spatial and temporal characterization of SCIAMACHY limb pointing errors during the first three years of the mission, Atmos. Chem. Phys., 5, 2593-2602, doi:10.5194/acp-5-2593-2005, 2005.

Walter, H. H., Landgraf, J., Spada, F., and Doicu, A.: Linearization of a radiative transfer model in spherical geometry, J. Geophys. Res., 111, D24304, doi:10.1029/2005JD007014, 2006.

Wang, Z., Barlage, M., Zeng, X., Dickinson, R. E., and Schaaf, C. B.: The solar zenith angle dependence of desert albedo, Geophys. Res. Lett., 32, L05403, doi:10.1029/2004GL021835, 2005.

Yue, G. K.: Retrieval of aerosol size distributions and integral properties from simulated extinction measurements at SAGE III wavelengths by the linear minimizing error method, J. Geophys. Res., 105, 14719-14736, 2000. 